\title{
A straightened proof for the uncountability of $\mathbb{R}$
}

\begin{abstract}
Andreas M. Hinz
Andreas M. Hinz received his doctoral degree and his habilitation in mathematics from the University of Munich (LMU), where he is now "außerplanmäßiger Professor" in addition to his current professorship for Applied Mathematics at the FernUniversität in Hagen. His main fields of research are real analysis, the history of science, mathematical modelling, and discrete mathematics.
\end{abstract}

In re mathematica ars proponendi quaestionem pluris facienda est quam solvendi.

G. Cantor, 1867 [8, p. 31]

In 1873, Georg Cantor (1845-1918) presented the first proof of the uncountability of the set of real numbers by establishing essentially the following statement.

Theorem. For every sequence of real numbers $\left(x_{n}\right)_{n \in \mathbb{N}}$, there is an $\left.x_{0} \in\right] 0,1[$ with $x_{0} \neq x_{n}$ for all $n \in \mathbb{N}$.

Cantor's proof of this result $[2, \S 2]$ makes use of nested intervals, but today a proof based on another ingenious idea of Cantor is more popular, namely the diagonal method, which he introduced in 1891 to prove the uncountability of $2^{\mathbb{N}}$ [3]. However, Cantor himself did not employ diagonalization directly in the proof of uncountability of $\mathbb{R}$, but gave a rather intricate derivation of $\left|2^{\mathbb{N}}\right|=|\mathbb{R}|$ in $[4, \S 4]$. The origin of the now standard argument for

Der heute gebräuchliche Beweis für die Überabzählbarkeit der Menge der reellen Zahlen stützt sich auf das sogenannte zweite Diagonalisierungsverfahren von Cantor, das dieser jedoch zum Nachweis der Überabzählbarkeit der Potenzmenge der natürlichen Zahlen verwandt hatte. Wegen der Nicht-Eindeutigkeit der üblicherweise eingesetzten Dezimaldarstellung reeller Zahlen müssen aber künstliche Zusatzbedingungen gestellt werden, die im Dualsystem versagen. Dies wurde von Fraenkel beobachtet, dessen Ausweg in der Betrachtung einer ,flacheren“ Diagonalen bestand. Doch auch sein Argument enthält eine Bedingung an die Dualdarstellung der Diagonalenelemente. Im vorliegenden Beitrag wird nun ein von Zahlensystem und Darstellung unabhängiger Beweis vorgestellt. 
the theorem is unknown (to me). It starts off from decimal representations

$$
\left|x_{n}\right|=\sum_{k \in \mathbb{Z}} x_{n, k} \cdot 10^{-k}, \quad x_{n, k} \in\{0, \ldots, 9\},
$$

and assigns a digit different from $x_{n, n}$ to $x_{0, n}$. To avoid the possibility that $x_{0}$ coincides with some $x_{n}$ which has two decimal representations, one might either assume that for these the (unique) finite representation had been chosen and exclude 9 as a value of $x_{0, n}$ (w.l., 0 is a member of $\left(x_{n}\right)_{n \in \mathbb{N}}$, such that $x_{0} \neq 0$ ), or one might restrict the values for $x_{0, n}$ to $\{1, \ldots, 8\}$ in the first place.

Presumably, it is this "classical procedure" which David Hilbert (1862-1943) considered worth explicating to Albert Einstein (1879-1955), and "Einstein, who seized everything immediately, was totally overwhelmed by the splendor of these thoughts..." (translated from a letter (1918) of Hilbert to Cantor's daughter Else, as quoted in [7, p. 176]). On the other hand, the same proof stirred a lot of controversy among lesser minds, even leading to a court case (cf. [6]).

Although ennobled by its inclusion in The Book [1, p. 92f] and therefore regarded as perfect $[1, \mathrm{p} . \mathrm{V}]$, this proof has the disadvantage of being rather artificial in the construction of the wanted number, depending on the base $p$ of the number system employed and, more seriously, it does not work at all for the dual system! (The second variant even has problems in base $p=3$, which can, however, be overcome by putting $x_{0, n}=1$, if $x_{n, n} \neq 1$, and otherwise $x_{0, n}=0$, if $n$ is odd, and $x_{0, n}=2$, if $n$ is even.) This was noted by Abraham Fraenkel (1891-1965) [5, p. 66f], whose way out was to insert bits 0 into the binary expansion of $x_{0}$ between any two switched entries from the sequence of reals, thereby using a less inclined diagonal. Again, this only works if a representation not ending in $1 \mathrm{~s}$ is assumed for all numbers. Therefore we propose the following most straightforward proof of the theorem for base $p=2$.

Proof. Let

$$
\forall n \in \mathbb{N}:\left|x_{n}\right|=\sum_{k \in \mathbb{Z}} x_{n, k} \cdot 2^{-k}, \quad x_{n, k} \in\{0,1\},
$$

and define

$$
\forall n \in \mathbb{N}: x_{0,2 n-1}=x_{n, 2 n}, \quad x_{0,2 n}=1-x_{n, 2 n},
$$

and

$$
x_{0}=\sum_{k \in \mathbb{N}} x_{0, k} \cdot 2^{-k} .
$$

Then $\left(x_{0, k}\right)_{k \in \mathbb{N}}$ is not eventually constant since $x_{0,2 n-1} \neq x_{0,2 n}$ and therefore $\left.x_{0} \in\right] 0,1[$ and $\forall n \in \mathbb{N}: x_{0} \neq x_{n}$ because $x_{0,2 n} \neq x_{n, 2 n}$.

This proof does not depend on the base $p$ of the number system, because we may put $x_{0,2 n}=\left(x_{n, 2 n}+1\right) \bmod p$. It is constructive in the sense of Cantor, who asserts that one can determine ("bestimmen") $x_{0}$ in the theorem. In fact, since he had shown in $[2, \S 1]$ that the set of algebraic numbers can be arranged in a sequence $\left(x_{n}\right)_{n \in \mathbb{N}}$, the corresponding $x_{0}$ from our proof of the theorem is an explicit transcendental number.

Acknowledgement. I am grateful to Günter M. Ziegler for a valuable discussion. 


\section{References}

[1] Aigner, M.; Ziegler, G.M.: Proofs from THE BOOK. Springer, Berlin 1998.

[2] Cantor, G.: Ueber eine Eigenschaft des Inbegriffs aller reellen algebraischen Zahlen. J. Reine Angew. Math. 77 (1874), 258-262 (= [8, pp. 115-118]).

[3] Cantor, G.: Ueber eine elementare Frage der Mannigfaltigkeitslehre. Jahresber. Deutsch. Math.-Verein. 1 (1890-91), 75-78 (= [8, pp. 278-280])

[4] Cantor, G.: Beiträge zur Begründung der transfiniten Mengenlehre (Erster Artikel). Math. Ann. 46 (1895), 481-512 (= [8, pp. 282-311]).

[5] Fraenkel, A.A.: Abstract set theory. North-Holland, Amsterdam 1953

[6] Hodges, W.: An editor recalls some hopeless papers. Bull. Symbolic Logic 4 (1998), 1-16.

[7] Meschkowski, H.: Probleme des Unendlichen. Vieweg, Braunschweig 1967.

[8] Zermelo, E. (ed.): Georg Cantor, Gesammelte Abhandlungen. Springer, Berlin 1932.

Andreas M. Hinz

Mathematisches Institut

Ludwig-Maximilians-Universität München

Theresienstraße 39

D-80333 München, Germany

e-mail: hinz@math.lmu.de

and

Fakultät für Mathematik und Informatik

FernUniversität in Hagen

Postfach 940

D-58084 Hagen, Germany

e-mail: andreas.hinz@fernuni-hagen.de 